\title{
Alignment and Micro-Inspection System
}

\author{
R. L. Hodgin, K. Moua, H. H. Chau
}

September 15, 1998

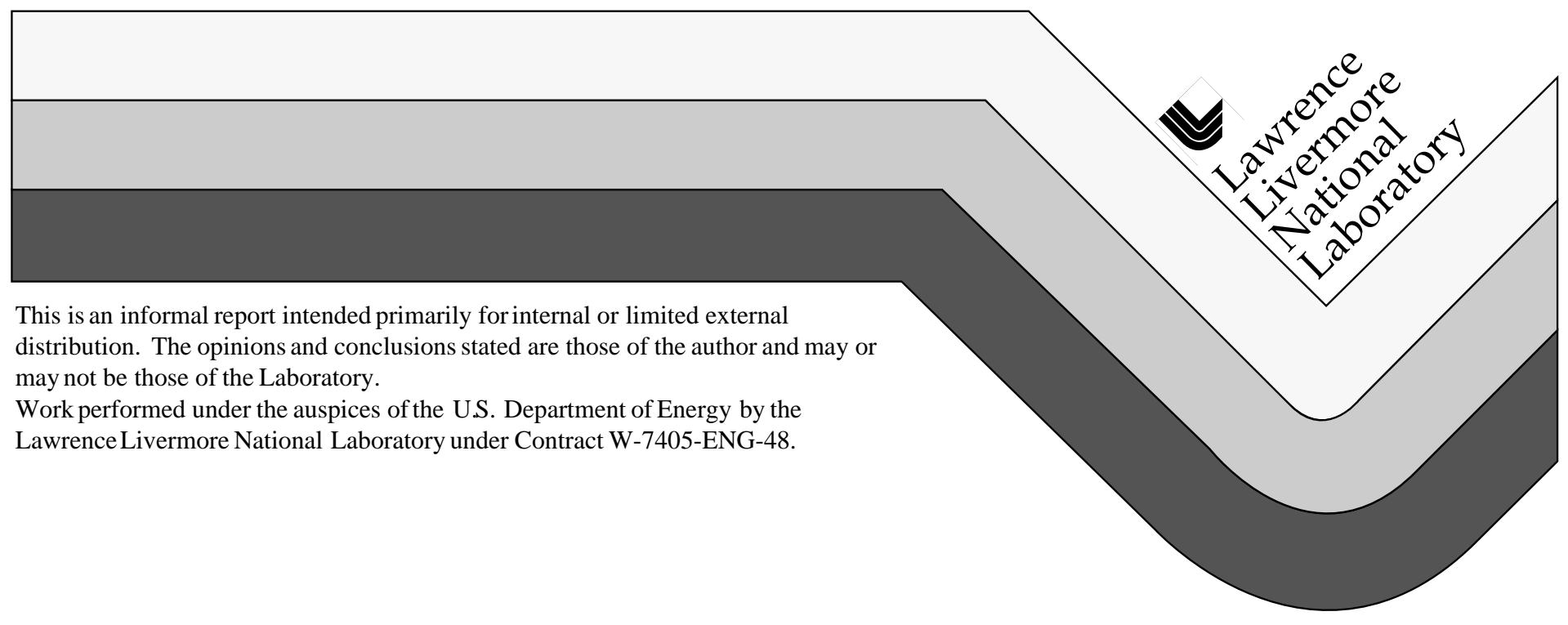




\section{DISCLAIMER}

This document was prepared as an account of work sponsored by an agency of the United States Government. Neither the United States Government nor the University of California nor any of their employees, makes any warranty, express or implied, or assumes any legal liability or responsibility for the accuracy, completeness, or usefulness of any information, apparatus, product, or process disclosed, or represents that its use would not infringe privately owned rights. Reference herein to any specific commercial product, process, or service by trade name, trademark, manufacturer, or otherwise, does not necessarily constitute or imply its endorsement, recommendation, or favoring by the United States Government or the University of California. The views and opinions of authors expressed herein do not necessarily state or reflect those of the United States Government or the University of California, and shall not be used for advertising or product endorsement purposes.

This report has been reproduced directly from the best available copy.

Available to DOE and DOE contractors from the Office of Scientific and Technical Information P.O. Box 62, Oak Ridge, TN 37831

Prices available from (423) 576-8401

Available to the public from the National Technical Information Service

U.S. Department of Commerce 5285 Port Royal Rd. Springfield, VA 22161 


\title{
ALIGNMENT AND MICRO-INSPECTION SYSTEM
}

\author{
R. L. HODGIN, K. MOUA, and H. H. CHAU
}

A video microscope system has been designed and installed in the C-tank, a 3-g, high-explosive firing chamber in HEAF (High Explosives Applications Facility in LLNL). This microscope system helps a great deal, not only for precision alignment of the laser beam on the minute target for the Fabry-Perot velocimeter, but also for in situ inspection of the target before and after the experiment. In addition, the video information can also be stored in the PC computer as database documentation.

\section{INTRODUCTION}

In our studies of detonators and mini-slappers using the C-tank facilities, alignment of the Argon laser beam for the Fabry-Perot velocimetric diagnostics was always an inconvenient and painful undertaking. The target size is of the order of $0.2 \mathrm{~mm}$ and the spot size of the focused laser beam is about $40 \mu \mathrm{m}$. With an unreliable reflection-pattern technique that was used previously, we missed the target and got the wrong results quite often because of the laser misalignment. Moreover, there was no way we could inspect and examine the target object in situ before and after the shot. We were motivated by these needs to design a simple system to improve not only the alignment procedure, but also the probability of a successful experiment.

\section{MECHANICAL SET-UP}

The C-tank is a small HE firing tank with $90 \mathrm{~cm}$ OD and $65 \mathrm{~cm}$ working ID. Under such space-constrained conditions, the first requirement for a precision alignment system is a sturdy and movable unit that can reach in-and-out easily to the target through the tank opening. Because the side of the tank is close to the room wall (only $1 \mathrm{~m}$ from the center of the tank to the wall), we built a sturdy, double-fold-swing-arms that was rigidly cantilevered from the wall with the alignment optics attached to the end. Fig.1 is a sketch of the mounting mechanism, showing the folding arm opened into the tank for alignment and closed to the wall for resting if not in service. Fig.2 is a picture of the system positioned for laser alignment and inspection at the opening of the C-tank.

The second requirement for the system is the precision alignment of the viewing optics. We built a stage with 6-degrees of freedom. They are the $\mathrm{x}, \mathrm{y}, \mathrm{z}$ linear translations, rotation around the stage axis plus twoway tilting i.e. front and back; left and right. A sketch of the optical stage is shown in Fig.3. There are two $\mathrm{x}$-direction translation stages. The bottom one is for positioning of the whole viewing assembly, while the top one is for focusing of the video camera. Fig.4 is a picture of the whole optical stage.

The laser beam from the Fabry-Perot Velocimeter comes down vertically onto the target object. In order to have a good view of the object without blocking the laser beam, we chose a turning mirror to bend the image into the horizontal direction, as shown in Fig. 3. For object illumination, a fiber-optic-ring-light guide is used, which is mounted directly above the target (refer to Fig. 3 ) to provide a bright, $360^{\circ}$ even, cool white, shadow-free illumination.

\section{LENS and CAMERA}

The heart of the system and its most important component is the lens and video camera. Other than the necessary requirements of the optics, i.e. the image magnification, the object resolution, distortion and the depth of field etc., our attention was drawn to the working distance of the objective lens, because we needed room to align the laser on the target. A macro CCD vario-lens (zoom) was selected for our system. It has an approximate constant working distance of $98 \mathrm{~mm} \pm 4 \mathrm{~mm}$ with enlargements from 0.8 to $4 \mathrm{x}$. The resolution with reference to object is from $22 \mu \mathrm{m}$ to $4 \mu \mathrm{m}$ and the depth of field is $\pm 0.5 \mathrm{~mm}$ to $\pm 0.1 \mathrm{~mm}$. The lens is made by Rodenstock and a sketch is shown in Fig.5. 
For the video camera, we selected a high-resolution color CCD camera. Normally, color cameras use a striped filter over a single CCD to separate chromatic information. The net result is a decrease in resolution and unreliable color reproduction. The camera we chose (Panasonic GP-US502) uses an optical prism for directing the image to three different CCD's and is then filtered to yield separate red, blue and green signals. The result is an extended chromatic dynamic range usually seen only with black and white cameras. In addition to the color abilities, there is an added benefit of the 3-CCD design. Many times it is preferable to view an image in black and white to improve contrast between objects. By using the blue only function available on the color monitor, the GP-US502 effectively becomes a high-resolution black and white camera.

The camera has $700 \mathrm{TV}$ lines of horizontal resolution. There are three _-inch interline transfer CCD's in the camera, each with $768(\mathrm{H}) \times 494(\mathrm{~V})$ pixels. Fig.6 is a picture of the camera head and its control chassis. For image display of the system, we use a 14-inch Sony color monitor that has 800 TV lines resolution. This results in a total overall magnification, optically times electronically, from $36 \mathrm{x}$ to $180 \mathrm{x}$ continuously. This performance is very satisfactory for meeting our requirements.

\section{CONCLUSIONS}

The installation and operation of the system have greatly improved the formerly tedious laser alignment process and inspection in C-tank. The merit of the system lies in its simplicity, flexibility, reliability and portability. For example, Fig. 7 is a picture illustrating the laser focusing on the center of the exploding bridge of $0.63 \mathrm{~mm} \times 0.63 \mathrm{~mm}$ inside a plastic barrel. Fig. 8 shows the remain of the exploded bridge. The video signals that are displayed on the monitor for instant inspection are also transmitted to the PC computer. With a simple single-frame-grabber card and software, the image information is stored and database documentation for the experiment is available. This added feature helps us organize our testing results completed with images, which are very useful for future reference.

\section{ACKNOWLEDGEMENTS}

It is our pleasure to acknowledge the support of Ron Lee, Initiation Group Leader, and for his encouragement during the construction of the system. We also thank Cal Gillespie for his helpful suggestions in the design and optics selections. 


\section{PICTURE CAPTIONS}

Fig.1. A drawing of the mounting mechanism showing the folding arms and points of rotation.

Fig.2. A picture of the system at the opening of the C-tank.

Fig.3. A sketch of the optical platform with 6-degrees freedom of motions.

Fig.4. A picture of the optical platform.

Fig.5. Rodenstock Macro CCD vario-lens.

Fig.6. A picture of the CCD camera head and its control chassis.

Fig.7. A picture of the $0.63-\mathrm{mm}$ sq. Blue-Lite exploding bridge with the alignment laser focusing at its center. The plastic barrel is $0.76 \mathrm{~mm}$ dia.

Fig.8. Post-shot, in situ inspection of an exploded bridge (0.38-mm sq. Blue-Lite bridge). The attached scale is $0.125 \mathrm{~mm} / \mathrm{div}$. 
Fig\#1

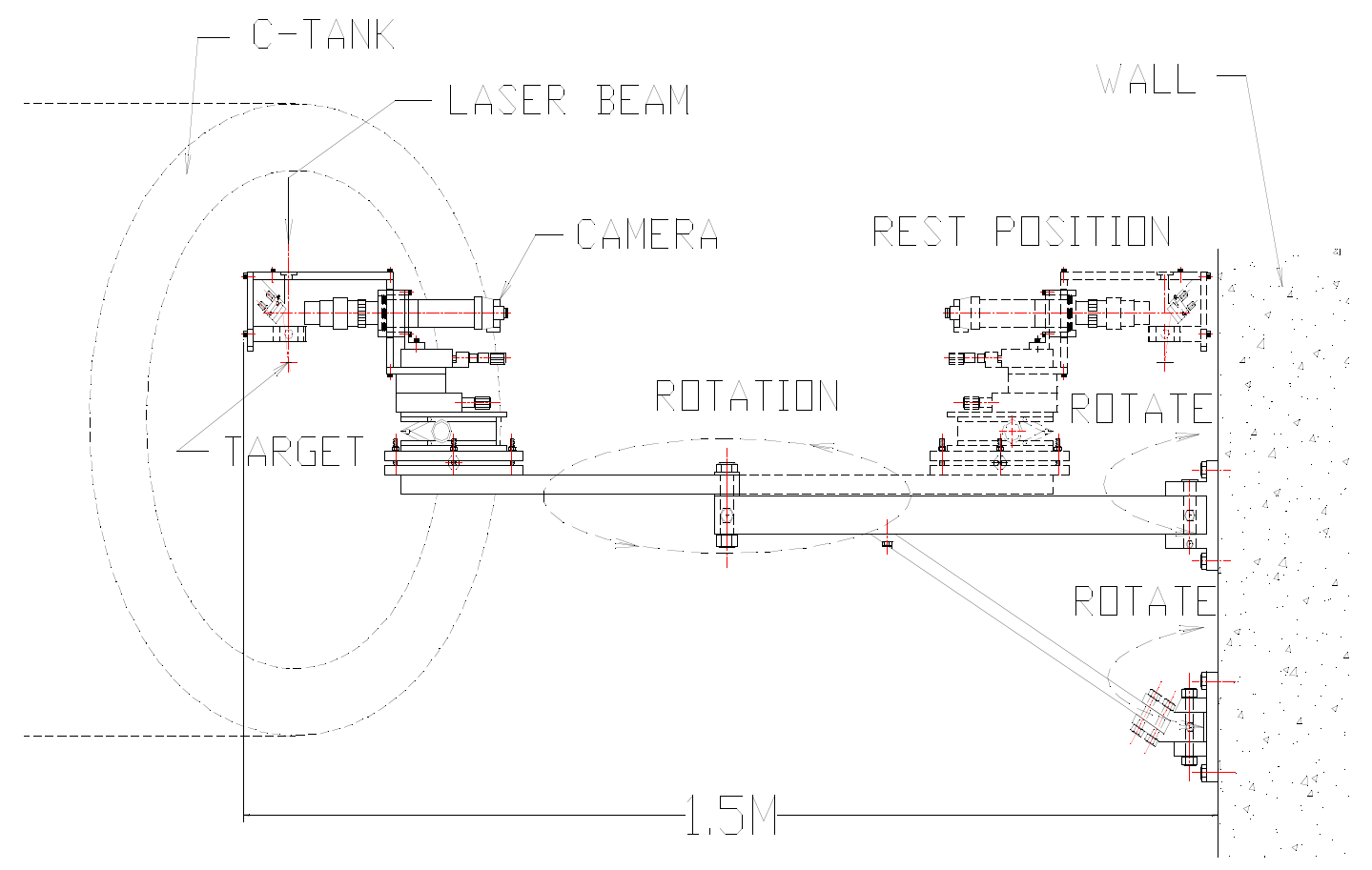


Fig\#2

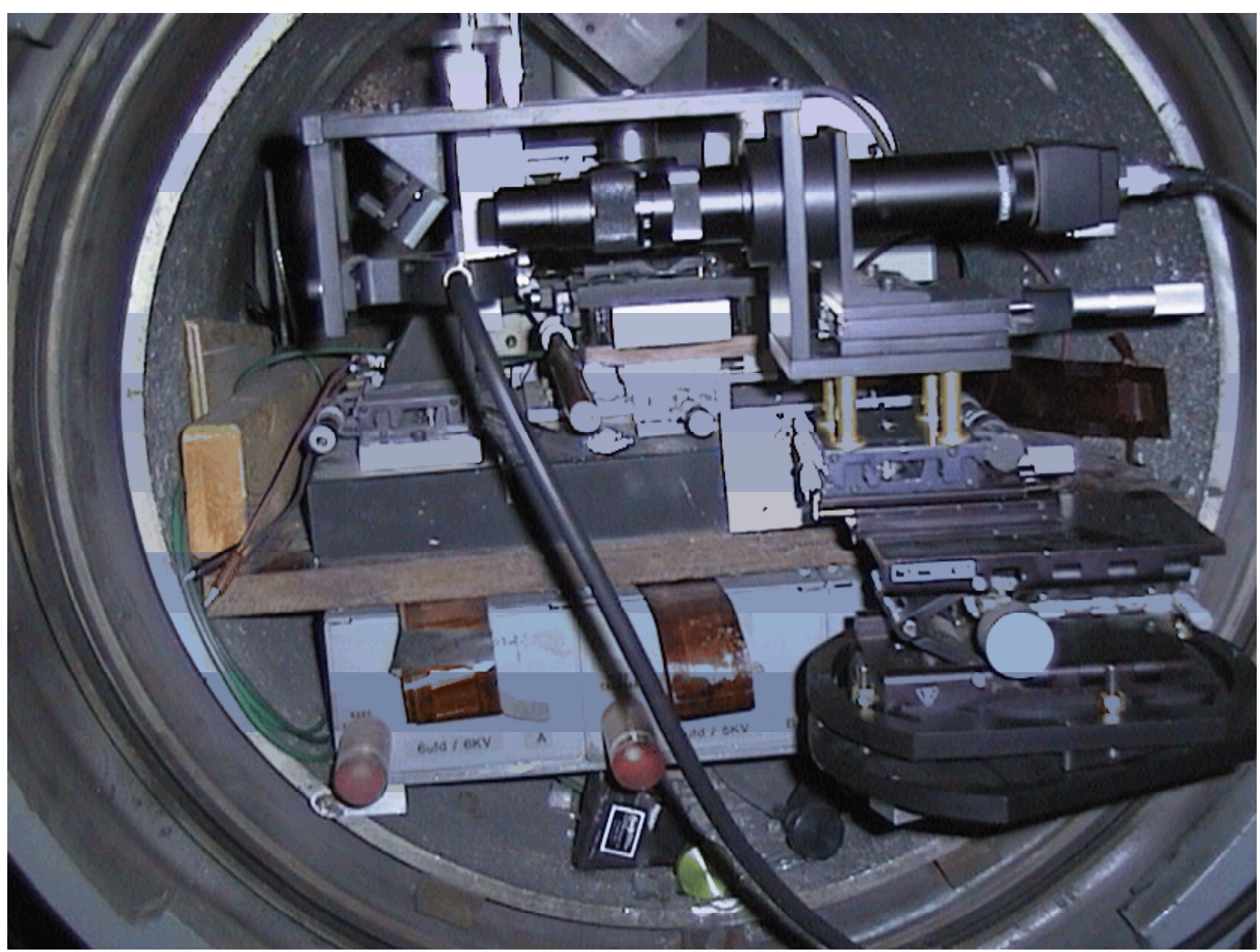


Fig\#3

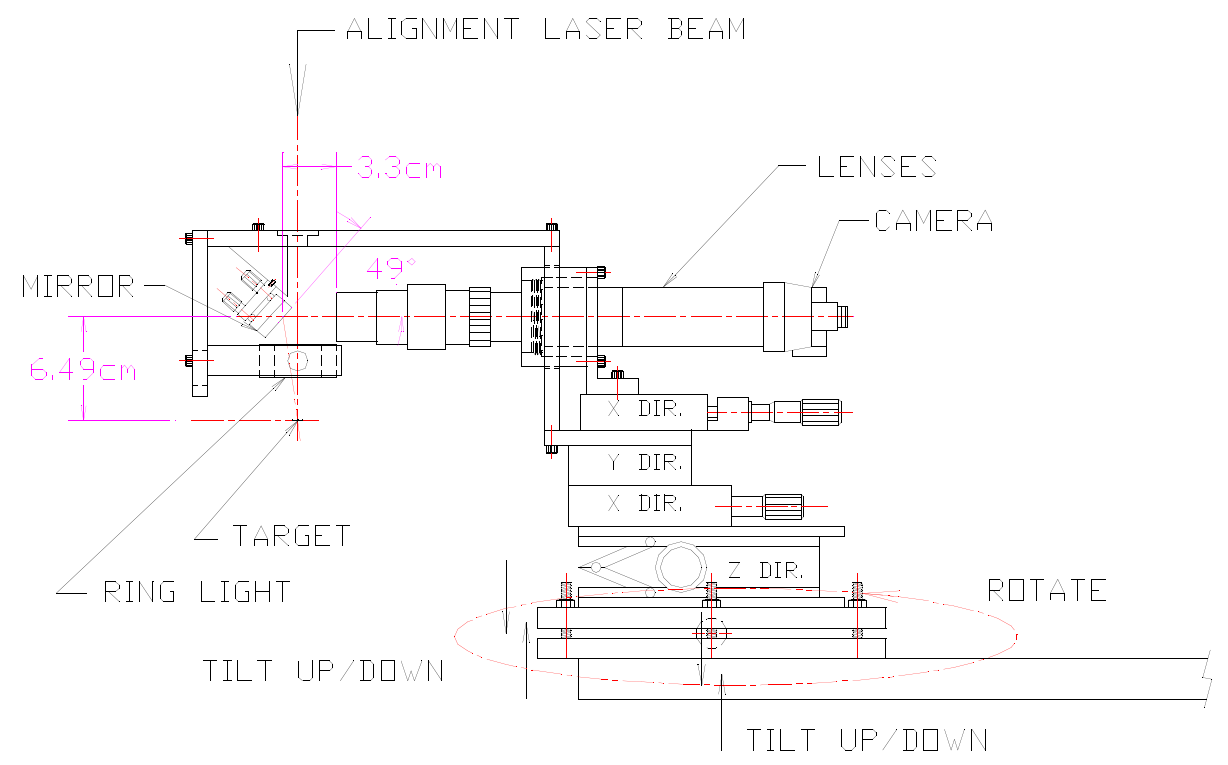


Fig\#4

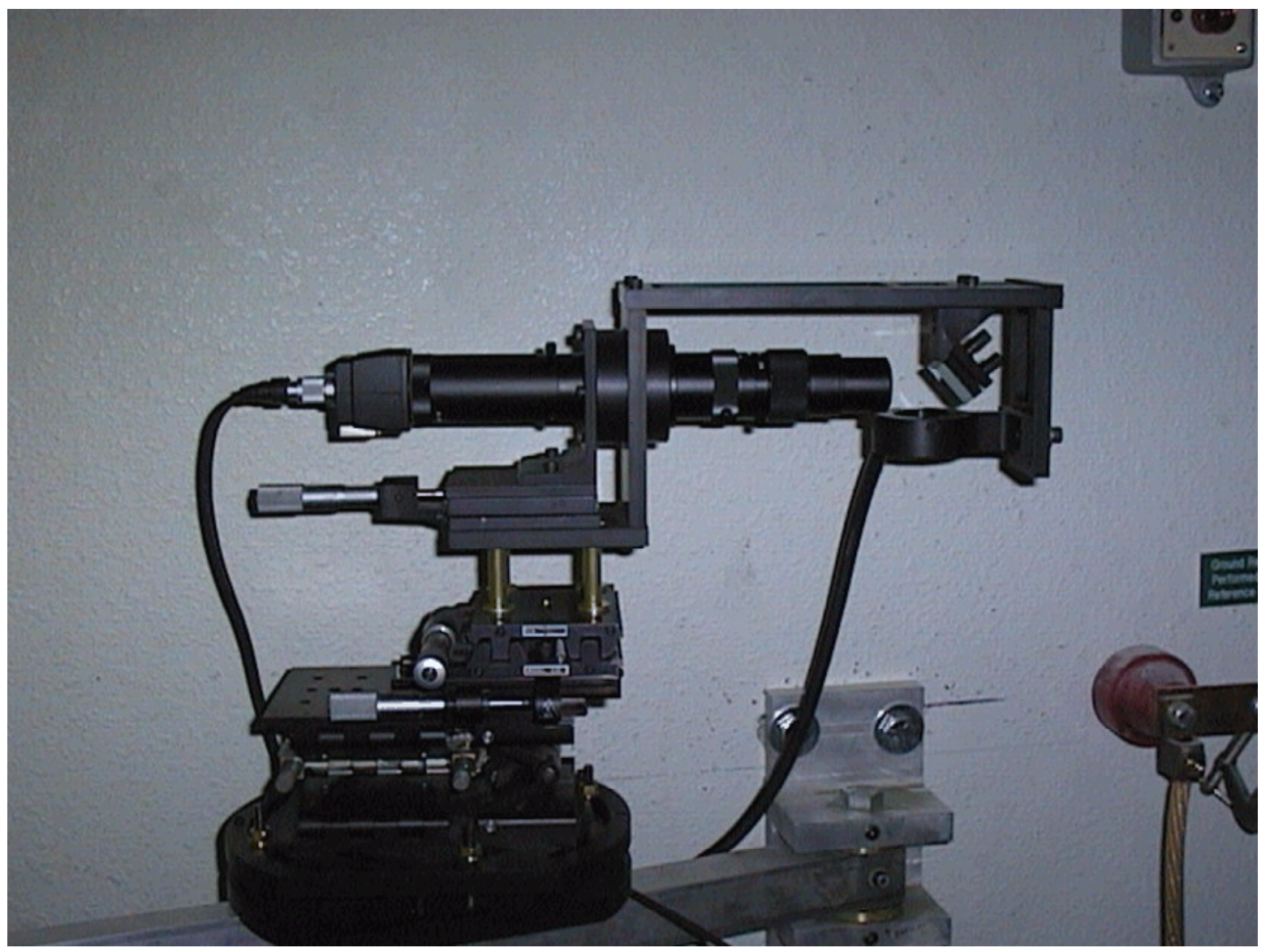


Fig\#5

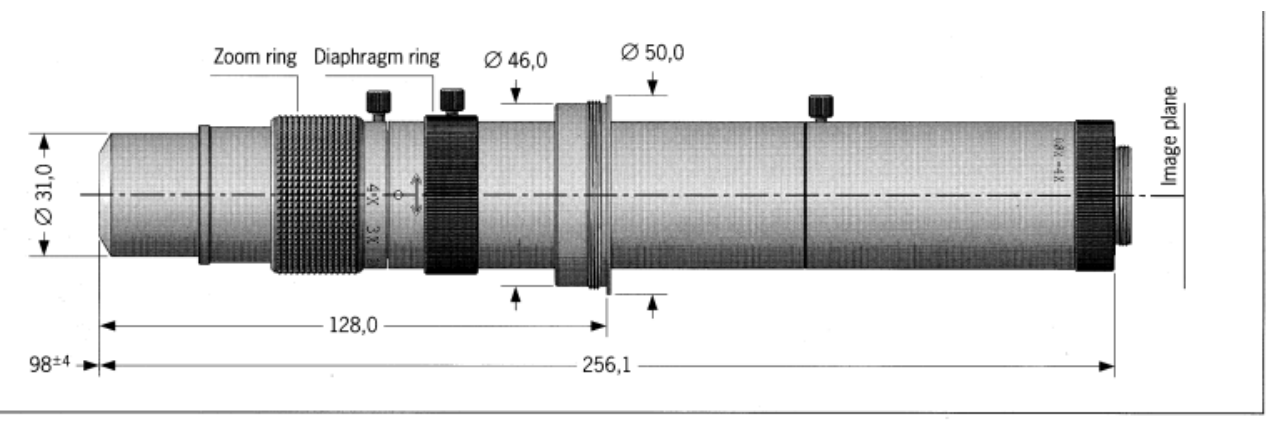


Fig \# 6

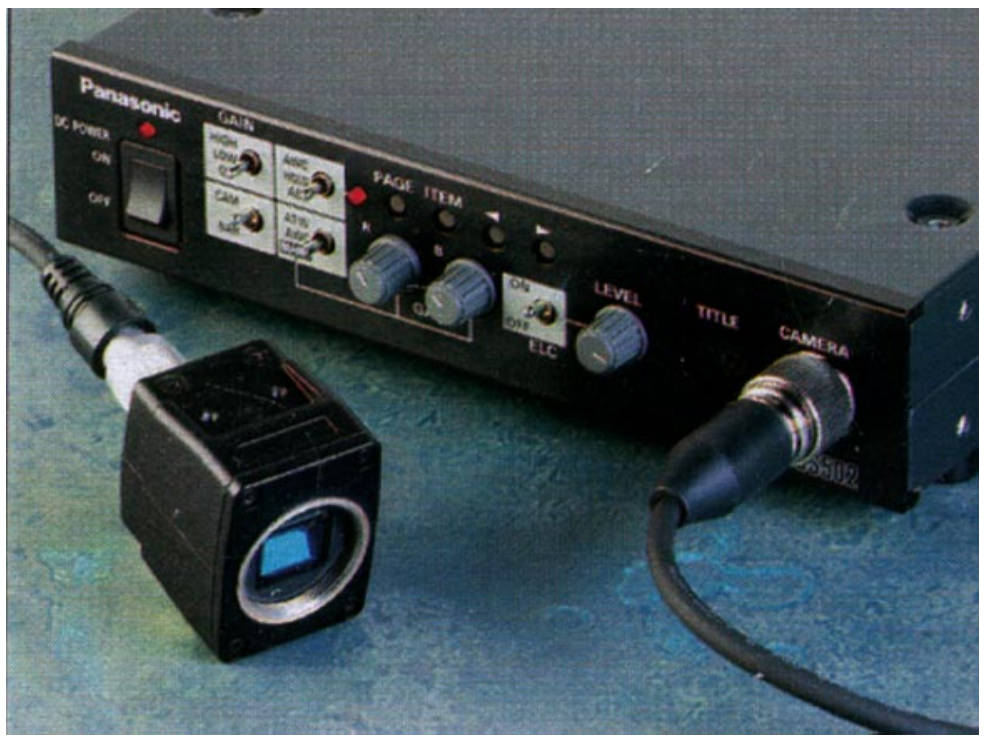


Fig\#7

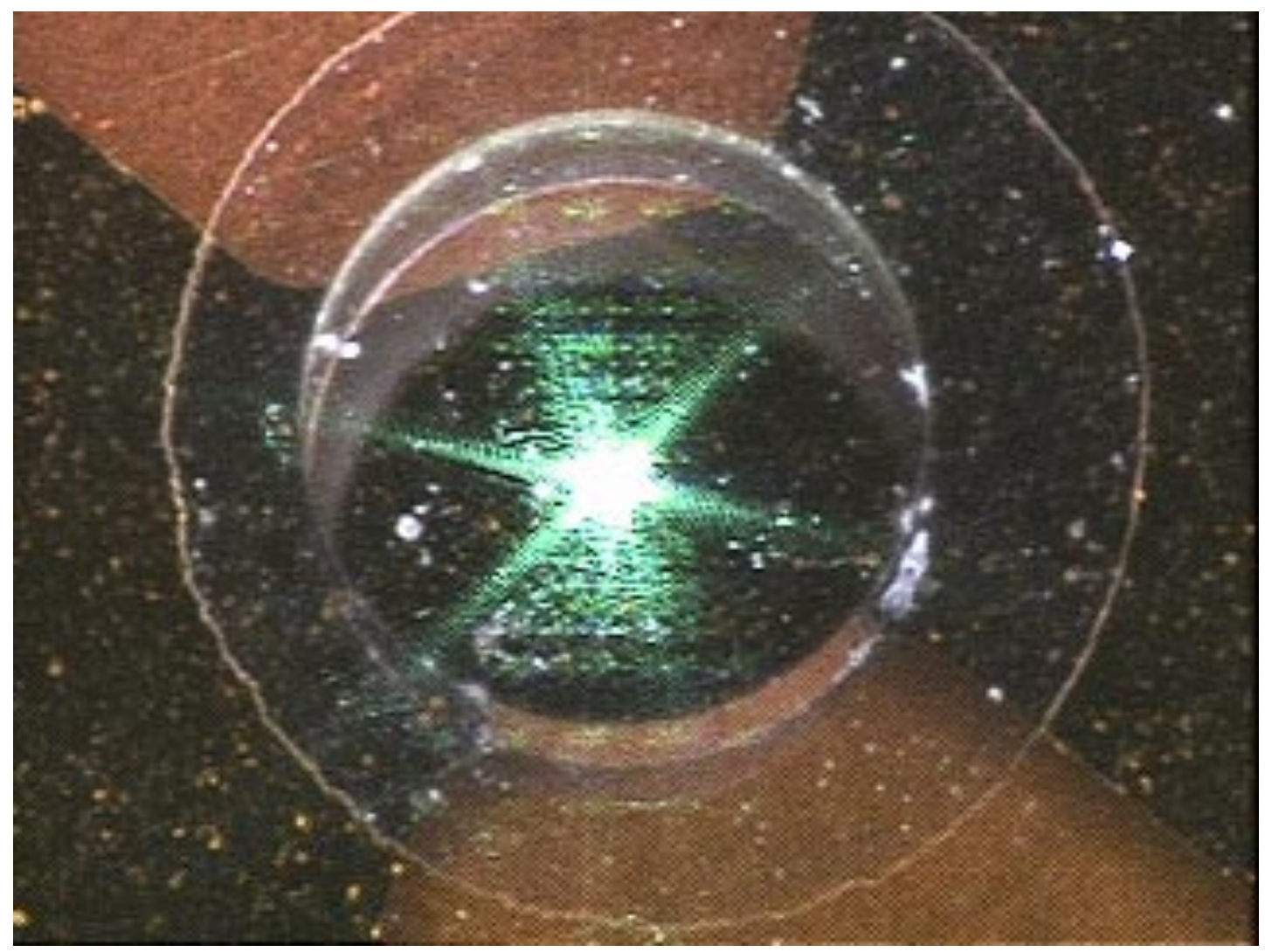


Fig\#8

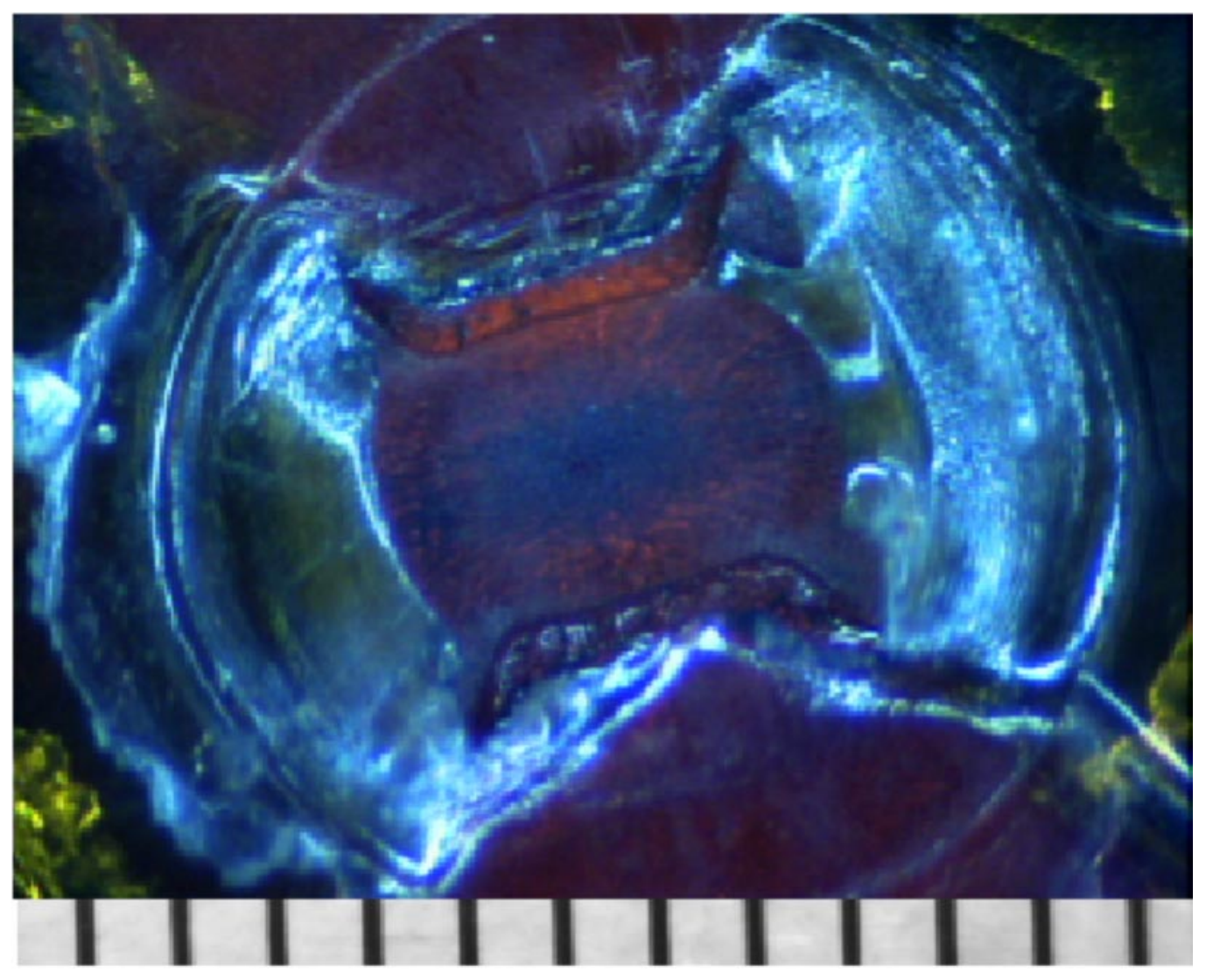

